\title{
ESTUDO DA SECAGEM PERIÓDICA DE MILHO EM LEITO FIXO
}

\author{
R. O. DEFENDI ${ }^{1}$, R. O. da SILVA ${ }^{1}$, P. R. PARAÍSO ${ }^{1}$ e L. M. de M. JORGE ${ }^{1}$ \\ ${ }^{1}$ Universidade Estadual de Maringá, Departamento de Engenharia Química \\ E-mail para contato: rafael.defendi@ hotmail.com / lmmj@deq.uem.br
}

\begin{abstract}
RESUMO - O Brasil é um dos líderes mundiais na produção e exportação de milho. Um dos principais gastos na cadeia produtiva deste grão está concentrado no processo de secagem necessário para garantir as condições ideais de armazenamento. Em pequenas propriedades o próprio silo de armazenamento pode ser utilizado como um silo secador, mediante a injeção de ar aquecido a vazão e temperatura constantes, caracterizando a secagem convencional. A secagem em operação periódica pode ser uma alternativa interessante por meio da qual é possível aumentar os transportes de massa e de energia entre o ar e o grão levando a uma diminuição na demanda energética do processo em comparação à operação convencional. Neste contexto, efetuou-se a modelagem, simulação e análise das duas formas de secagem: convencional e periódica, destacando-se as vantagens e limitações desta nova modalidade de secagem de grãos de milho.
\end{abstract}

\section{INTRODUÇÃO}

O Brasil é um dos maiores produtores e exportadores de grãos de milho. De acordo com dados da Conab referentes ao ano safra 2012/2013, o Brasil ficou em terceiro lugar entre os maiores exportadores de milho, atrás da China e dos Estados Unidos. O consumo nacional de milho está em torno de $66,7 \%$ da produção nacional, cujo valor esteve próximo a 78,5 milhões de toneladas em 2013. Segundo o Ministério da Agricultura Pecuária e Abastecimento, há uma previsão de crescimento da produção nacional de milho em torno de $19 \%$ para os próximos dez anos. Para garantir uma boa qualidade destes grãos durante sua cadeia produtiva é necessário que se faça uma armazenagem ideal que evite perdas deste material.

O armazenamento de grãos de milho é um processo necessário, uma vez que sua produção é periódica e as demandas das indústrias e do comércio são ininterruptas (Puzzi, 2000). Uma colheita realizada em dois meses pode ser consumida durante um ou mais anos. Contudo, muitos fatores podem prejudicar a qualidade destes grãos enquanto eles estão armazenados. De acordo com Puzzi (2000), estes fatores podem ser um agente físico (temperatura, teor de umidade, danos mecânicos) ou um agente biológico (microorganismos, insetos, fungos). Este autor ainda ressalta que é importante controlar e minimizar os efeitos provenientes destes fatores para garantir a qualidade e a composição química (carboidratos, gorduras, proteínas, fibras, minerais e vitaminas) destes grãos.

Observa-se que o teor de umidade é o fator predominante que controla a qualidade do grão estocado (Puzzi, 2000). Em baixos valores de umidade, as reações enzimáticas são reduzidas como também as taxas de respiração inerentes ao metabolismo do grão que podem levar o material à 


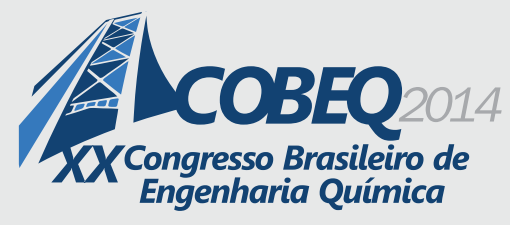

19 a 22 de outubro de 2014
Florianópolis/SC

podridão. O teor de umidade pode ser controlado pelo processo de secagem. Neste contexto, é importante secar grãos colhidos até níveis seguros de umidade para se alcançar um armazenamento ideal sem riscos de deterioração dos grãos (Puzzi, 2000; Martins et al., 2002). O nível seguro de teor de umidade para se armazenar o milho durante um ano é de $13 \%$ em base úmida e para períodos superiores a um ano é de 12\% em base úmida (Lazzari, 1993).

Muitos produtores brasileiros usam armazéns para estocar grãos e utilizam as condições naturais do ambiente para secar os grãos enquanto estes ainda estão na lavoura (Martins et al., 2002). Embora as condições do clima brasileiro sejam favoráveis, esta prática de secagem natural não tem sido eficiente para evitar perdas tanto quantitativas quanto qualitativas do material armazenado (Martins et $a l ., 2002)$. Por outro lado, a secagem forçada com ar quente pode garantir as condições ideais de armazenamento, possibilitando que o grão chegue a níveis de umidade satisfatórios para evitar estas perdas. Embora o processo de secagem com ar quente seja muito utilizado pelas indústrias de grãos, este processo encarece os custos de produção devido a grande demanda de energia necessária para movimentar e aquecer o ar de secagem (Biagi et al., 2002). De acordo com Silva et al. (2000), a secagem em temperaturas altas pode consumir $60 \%$ ou mais do total de energia usada na produção de produtos agrícolas.

Neste contexto, este trabalho visa estudar uma alternativa para reduzir estes custos por meio da operação periódica, a qual pode potencializar os transportes de massa e de energia envolvidos no processo proporcionando uma redução no consumo energético. A operação periódica consiste numa contínua modulação das condições operacionais (como a temperatura e a velocidade do ar) numa específica frequência e amplitude. Como as taxas de secagem não são linearmente dependentes da temperatura do ar, a operação periódica pode alcançar uma eficiência maior em comparação a operação convencional (realizada com temperatura e vazão do ar constantes) em processos em que ambas as operações são tomadas com o mesmo gasto energético e tempo de secagem.

O estudo da secagem periódica de grãos é recente e há poucas referências sobre este assunto atualmente. Contudo, alguns autores estudaram a operação periódica em reatores químicos onde observaram que a modulação das condições dos reagentes pode melhorar o rendimento do reator (Silveston e Hanika, 2004; Lange et al., 1999; Rouge et al., 2001; Tukac et al., 2007). De acordo com Silveston e Hanika (2004), a operação periódica em reatores trifásicos pode mudar a seletividade e aumentar tanto a conversão quanto o rendimento. Estes autores ainda acrescentam que as taxas de reação são potencializadas sob a periódica interrupção do fluxo para leitos gotejantes.

Na secagem de grãos, Romero et al. (2010) estudaram a secagem periódica de soja em leito profundo por meio de um modelo heterogêneo a duas fases. Neste estudo, estes autores observaram que a operação periódica pode melhorar o rendimento do secador e também reduzir o consumo energético em comparação à operação convencional.

Neste contexto, o objetivo deste trabalho foi efetuar a modelagem, a simulação e a análise das duas formas de secagem: a convencional e a periódica, destacando-se as vantagens e limitações desta nova modalidade na secagem de milho em camada delgada. As simulações foram realizadas em condições de mesmo gasto energético e mesmo tempo de secagem para ambas as operações por meio 
de um modelo matemático baseado em dados cinéticos de secagem de milho obtidos em camada delgada.

\section{METODOLOGIA}

\subsection{Modelo Matemático}

O modelo matemático está baseado num balanço de massa relacionado à quantidade de água que evapora em um grão ao longo do tempo de secagem. O acúmulo de água dentro do grão é igual a quantidade água que é evaporada com o tempo:

$$
\frac{d M}{d t}=-\frac{K s \cdot A}{m_{s}} \cdot\left(M-M_{e}\right)
$$

Onde Ks é o coeficiente global de transferência de massa, A é a área superficial do grão, M é o teor de umidade do milho em base seca, $\mathrm{M}_{\mathrm{e}}$ é o teor de umidade do milho de equilíbrio, $\mathrm{m}_{\mathrm{s}}$ é a massa do grão de milho totalmente seco e t é o tempo. Como o valor da área superficial do grão é difícil de ser estimado, considerou-se a seguinte relação:

$$
K=\frac{K s \cdot A}{m_{s}}
$$

Onde $\mathrm{K}$ é um coeficiente global de transferência de massa relativo dado em $\mathrm{s}^{-1}$. Assim, o modelo matemático para secagem de milho em camada delgada resulta em:

$$
\frac{d M}{d t}=-K \cdot\left(M-M_{e}\right)
$$

Este modelo é uma analogia a Lei de Newton do Resfriamento e este já havia sido proposto por Lewis (1921). Esta equação também foi usada por outros autores na secagem de grãos em camada delgada (Elias et al., 2002). De acordo com Henderson e Perry (1955), esta equação descreve a taxa de remoção de umidade durante o período onde as taxas de secagem são decrescentes. Neste trabalho, este modelo foi usado para simular a operação periódica e convencional em camada delgada. Para isso, a equação utilizada para estimativa de $\mathrm{K}$ foi baseada na equação ajustada por Mancini et al. (2002), a qual segue abaixo:

$$
K_{s} a=K \cdot \rho_{s s}=(7,31-0,0177 \cdot T) \cdot M-(2,20-0,00618 \cdot T)
$$

Onde $K_{\mathrm{s}} \mathrm{a}$ é o coeficiente volumétrico de transferência de massa dado em $\mathrm{kg} / \mathrm{m}^{3} \mathrm{~s}$, $\rho_{\mathrm{ss}}$ é a massa específica do milho seco e T é a temperatura do ar dada em Kelvin. O valor da massa específica do milho foi estimado em base no estudo feito por Santos et al. (2012).

\subsection{Simulação da Operação Periódica e Convencional}

A equação do modelo (Equação 3) foi resolvida numericamente pelo método das diferenças finitas para frente. Nas simulações em operação periódica, foi modulada a temperatura do ar num 
formato senoidal como apresentado na Figura 1. Para cada simulação em operação periódica, uma simulação em operação convencional foi realizada com a temperatura do ar mantida constante no valor igual à média da temperatura do ar da respectiva operação periódica para garantir que ambas as operações fossem simuladas com o mesmo consumo energético referente ao aquecimento do ar. A expressão usada para o cálculo desse consumo energético está apresentada abaixo:

$$
E=G g \cdot \int_{0}^{t} c p_{a r} \cdot T \cdot d t
$$

Onde E é o consumo energético, Gg é a vazão mássica de ar e $\mathrm{cp}_{\mathrm{ar}}$ é o calor específico do ar. O valor da temperatura média da operação periódica, cujo valor equivale a temperatura constante em operação convencional foi calculado pela seguinte equação:

$$
\bar{T}=\frac{\int T \cdot d t}{\int d t}
$$

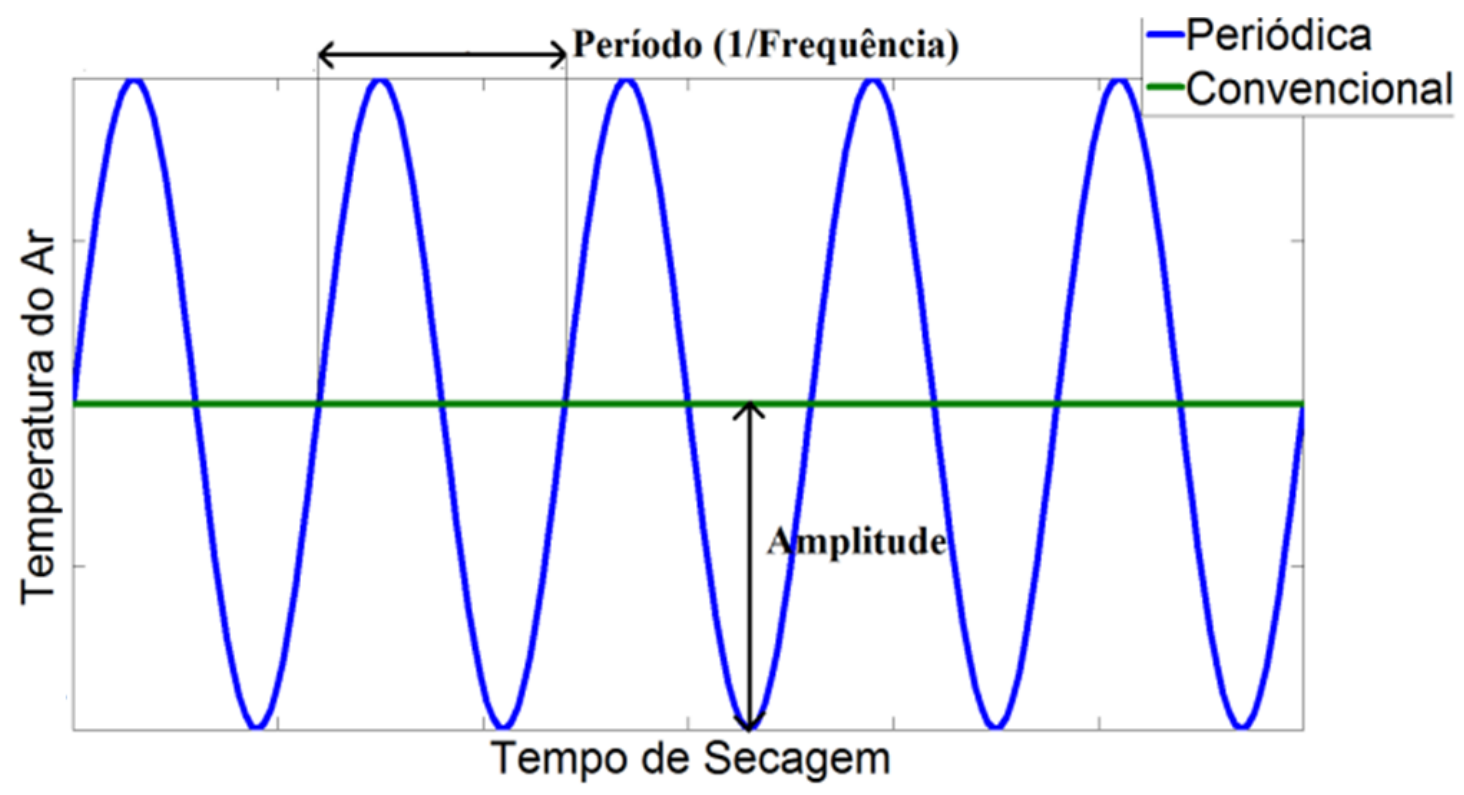

Figura 1 - Modulação da Temperatura do Ar

A equação usada para modular a temperatura do ar em operação periódica foi:

$$
T_{p}=\operatorname{Amp} \cdot \operatorname{sen}(\text { fr.t. } 2 \pi)+T_{c}
$$

Onde $\mathrm{T}_{\mathrm{p}}$ é a temperatura do ar em operação periódica, Amp é a amplitude em ${ }^{\circ} \mathrm{C}$, fr é a frequência em s $\mathrm{s}^{-1}$ e $\mathrm{T}_{\mathrm{c}}$ é a temperatura do ar em operação convencional. As simulações foram realizadas para períodos de 6 a 60 minutos e amplitudes de 7 a $20{ }^{\circ} \mathrm{C}$. O tempo de simulação foi igual para ambas as operações. A umidade inicial do milho foi tomada com o valor de $0,18 \mathrm{em}$ base seca e $\mathrm{o}$ ar de secagem foi considerado sem umidade. Nessas condições, a umidade de equilíbrio do milho foi considerada nula. 


\section{RESULTADOS E DISCUSSÕES}

Das simulações realizadas, observou-se que a operação periódica com modulação contínua da temperatura do ar pode ser mais vantajosa em comparação à operação convencional realizada com temperatura constante dependendo da amplitude e da frequência das oscilações da temperatura do ar. Verificou-se que a operação periódica pode aumentar as taxas de secagem, uma vez que foi possível atingir níveis menores de umidade de milho em casos em que ambas as operações, periódica e convencional, tiveram a mesma demanda energética inerente ao aquecimento do ar de secagem. A Figura 2 apresenta o perfil de umidade do grão de milho com o tempo de secagem para diferentes amplitudes inerentes a modulação da temperatura do ar. Neste gráfico, é possível observar que altos valores de amplitudes favorecem a operação periódica, pois quanto maior o valor da amplitude, menores foram os níveis de umidade do milho no final da secagem. Além disso, verificou-se que pequenas amplitudes, como o caso de $7^{\circ} \mathrm{C}$, a operação periódica apresentou um menor rendimento em comparação à operação convencional, pois a taxa de secagem foi menor, uma vez que o nível de umidade do grão foi superior ao nível em operação convencional.

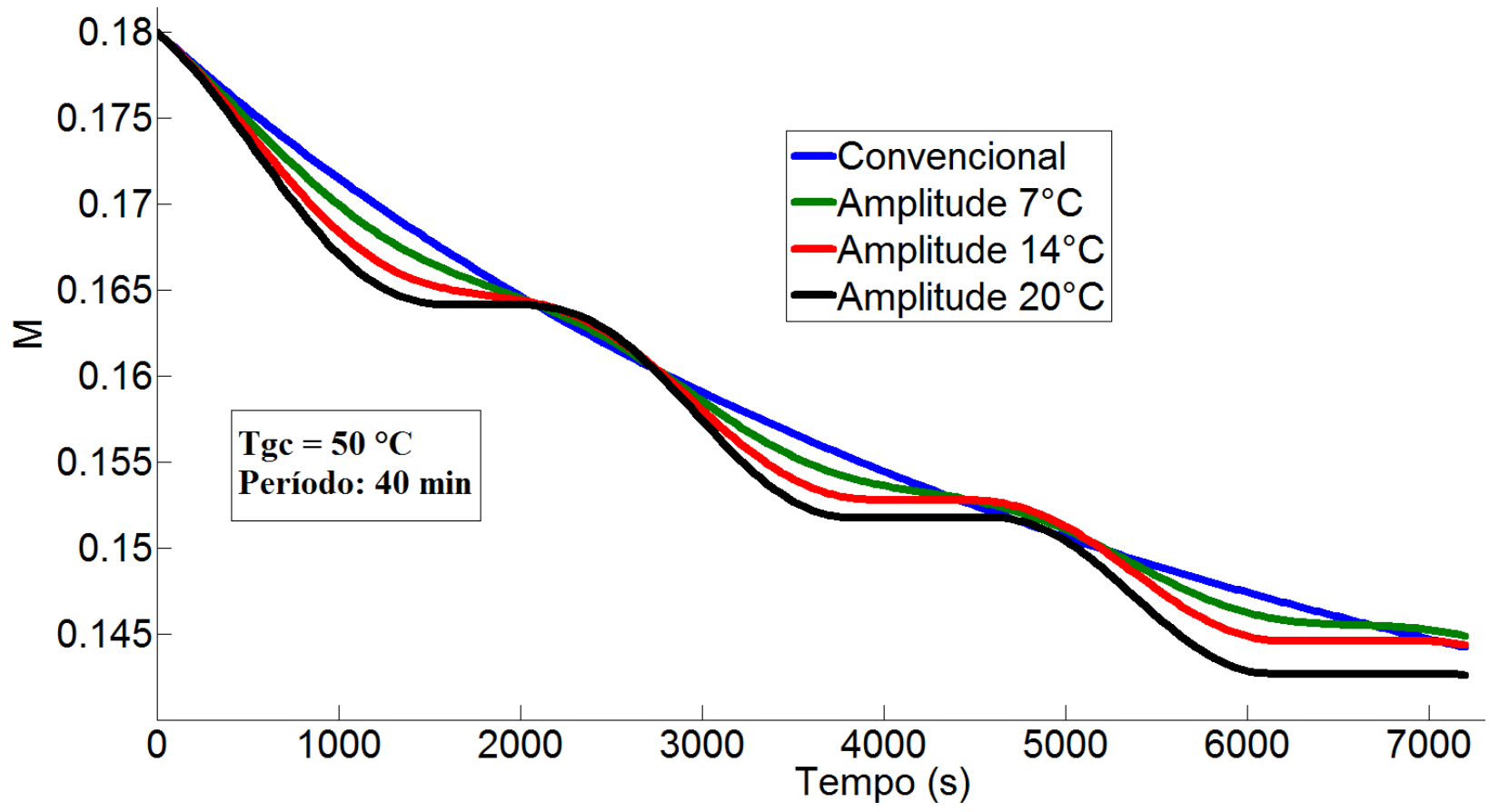

Figura 2 - Perfil de Umidade do Milho para Diferentes Amplitudes

Além disso, verificou-se que a operação periódica foi favorecida com o progresso da secagem, pois as taxas de secagem aumentaram com o tempo em comparação às taxas da operação convencional. A Figura 3 apresenta o perfil de umidade do milho para uma secagem de quatro horas de duração. É interessante comparar as duas operações, periódica e convencional, nos instantes em que se termina completamente uma oscilação da temperatura do ar, pois é neste instante em que o gasto energético de ambas as operações são similares. No gráfico da Figura 3, este instante ocorre 
quando ocorre uma mudança acentuada no perfil de umidade do grão, ou seja, é quando a temperatura do ar volta a aumentar, aumentando as taxas de secagem e diminuindo de forma mais acentuada os níveis do teor de umidade do grão. Observa-se que nas primeiras oscilações, a operação convencional chega a ser mais vantajosa, pois os níveis de umidade são menores nessa operação. Contudo, conforme o progresso da secagem ocorre uma melhora gradual do rendimento da operação periódica diminuindo a cada oscilação o nível de umidade do grão em comparação aos resultados em operação convencional. Assim, no final das quatro horas o nível de umidade do grão é menor operando periodicamente.

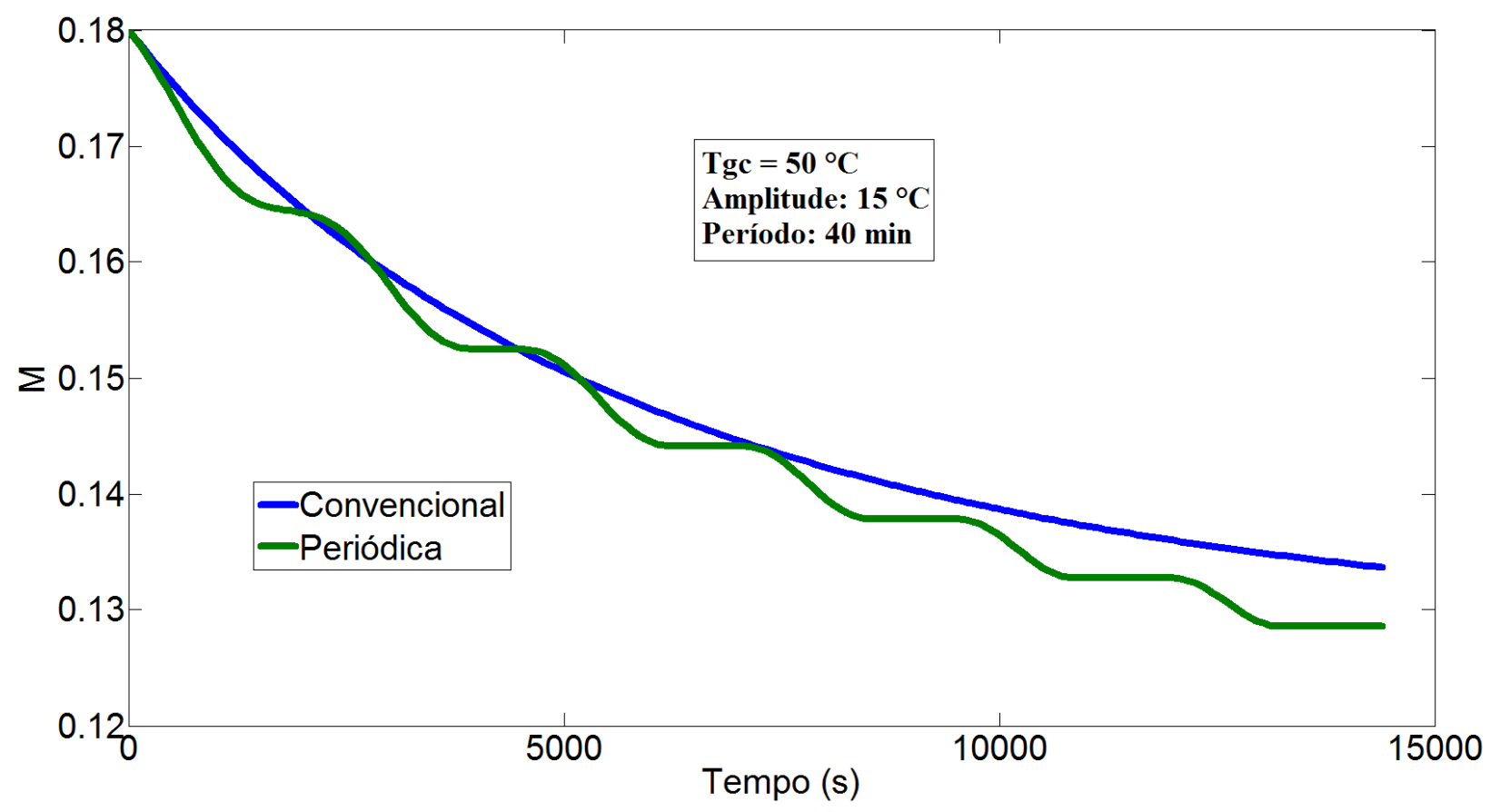

Figura 3 - Perfil de Umidade do Milho em Operação Convencional e Periódica

Quanto à variação dos períodos das oscilações da temperatura do ar, verificou-se que é interessante se trabalhar em baixos valores de períodos como apresenta a Figura 4 que ilustra o perfil de umidade do milho em diferentes frequências nas oscilações. É interessante comparar as diferentes operações periódicas deste gráfico nos tempos de uma, duas, três e quatro horas, momentos nos quais os gastos energéticos são equivalentes em todas as operações. Estes instantes são marcados pelos términos das oscilações do perfil de umidade do milho para a simulação realizada com período de 60 minutos. Observa-se que apesar de no final da secagem as umidades serem iguais para as diferentes operações periódicas, a operação com menor período (6 minutos) foi a que apresentou melhor comportamento durante toda a secagem, pois os níveis de umidade sempre foram menores em comparação à operação convencional e estes níveis em alguns momentos também foram menores em comparação as outras operações periódicas nos instantes nos quais os gastos energéticos eram equivalentes. 


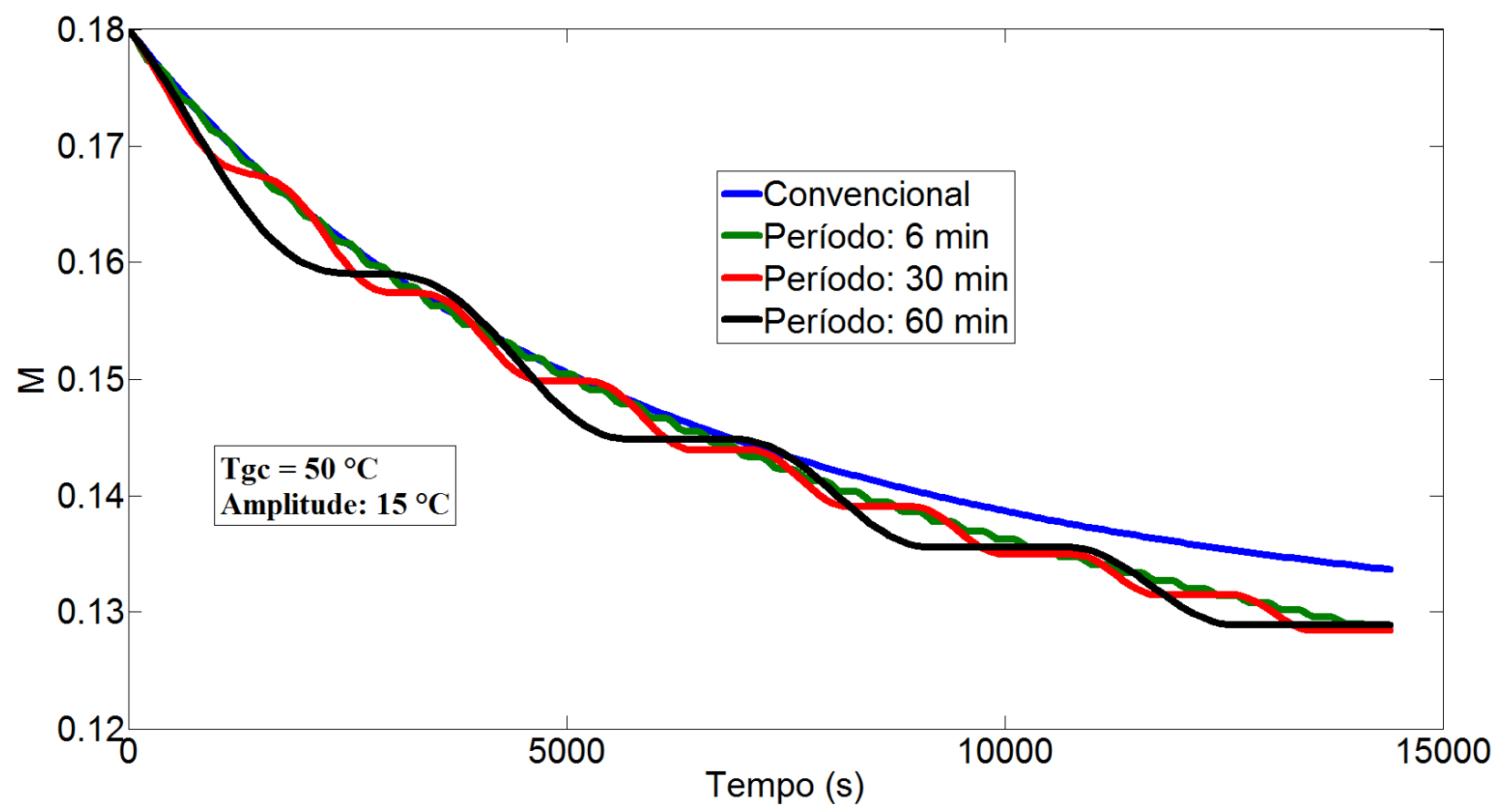

Figura 4 - Perfil de Umidade do Milho para Diferentes Períodos

\section{CONCLUSÃO}

Constatou-se que a operação com modulação periódica da temperatura do ar pode ser mais vantajosa em comparação a operação realizada em operação convencional, em casos em que ambas as operações demandaram o mesmo consumo energético, uma vez que as taxas de secagem podem ser maiores na operação periódica. Observou-se que há um favorecimento da operação periódica de secagem de milho em camada delgada para oscilações com altos valores de amplitudes e baixos valores de períodos.

\section{AGRADECIMENTOS}

O presente trabalho foi realizado com o apoio do Conselho Nacional de Desenvolvimento Científico e Tecnológico - $\mathrm{CNPq}$ - e com o apoio da Coordenação de Aperfeiçoamento de Pessoal de Nível Superior - CAPES - Brasil.

\section{REFERÊNCIAS}

BIAGI, J. D.; BERTOL, R.; CARNEIRO, M. C. Secagem de grãos para unidades centrais de armazenamento. In Armazenagem de Grãos. LORINI, I.; MIIKE, L. H.; SCUSSEL, V. M.; Campinas: Instituto Bio Geneziz, 2002; 289-307.

ELIAS, R. N.; BARBOSA, A. L. S.; MANCINI, M. C. Secagem de Grão de Bico em Leito Fixo. Revista Universidade Rural, Série Ciências Exatas e da Terra, v. 21 (1), p. 113-119, 2002. 


\section{9 a 22 de outubro de 2014 \\ Florianópolis/SC}

HENDERSON, S. M.; PERRY, R. L. Agricultural process engineering. New York: John Wiley \& Sons, Inc., 1955.

LANGE, R.; GUTSCHE, R.; HANIKA, J. Forced Periodic Operation of a Trickle-Bed Reactor. Chemical Engineering Science, v. 54, p. 2569-2573, 1999.

LAZZARI, F. A. Umidade, fungos e micotoxinas na qualidade de sementes, grãos e rações. Curitiba: Ed. Do Autor, 1993.

LEWIS, W. K. The Rate of Drying of Solid Materials. The Journal of Industrial and Engineering Chemistry, v. 13, p. 427-432, 1921.

MANCINI, M. C.; MASSARANI, G.; BICAIA JR., E. C. Transferência de Massa na Secagem de Milho em Secadores de Camada Espessa em Leitos Fixo e Deslizantes. Revista Universidade Rural, Série Ciências Exatas e da Terra, v. 21 (1), p. 121-129, 2002

MARTINS, R. M.; FRANCO, J. B. da R.; OLIVEIRA, A. V.; ANGONESE, C. Armazéns para propriedade familiar. In Armazenagem de Grãos. LORINI, I.; MIIKE, L. H.; SCUSSEL, V. M.; Campinas: Instituto Bio Genezizs, 2002; 117-155.

PUZZI, D. Abastecimento e Armazenagem de Grãos. Campinas: Instituto Campineiro de Ensino Agrícola, 2000.

ROMERO, J. A. da S.; OMOTO, E. S.; CONCEIÇÃO, W. A. dos S.; COUTINHO, M. R.; PARAÍSO, P. R.; JORGE, L. M. M. Estudo da secagem de soja em operação periódica. COBEQ XVIII Congresso Brasileiro de Engenharia Química, Foz do Iguaçú, Brasil, Setembro, 2010.

ROUGE, A.; SPOETZL, B.; GEBAUER, K.; SCHENK, R.; RENKEN, A. Microchannel reactors for fast periodic operation: the catalytic dehydration of isopropanol. Chemical Engineering Science, v. 56, p. 1419-1427, 2001.

SANTOS, C. C.; CANEPPELE, C.; BONFIM-SILVA, E. M. Massa Específica e Porosidade de Grãos pelo Método de Complementação de Líquidos. Enciclopédia Biosfera, Centro Científico Conhecer, v. 8 (15), p. 1178-1184, 2012

SILVA, J. S.; AFONSO, A. D. L.; DONZELLES, S. M. L. Secagem e Secadores. In Secagem e Armazenagem de Produtos Agrícolas. SILVA, J. S. Viçosa: Aprenda Fácil, 2000; 107-138.

SILVESTON, P. L.; HANIKA, J. Periodic Operation of Three-Phase Catalytic Reactors. The Canadian Journal of Chemical Engineering, v. 82, p. 1105-1142, 2004.

TUKAC, V.; HANIKA, J.; CHYBA, V. Periodic state of wet oxidation in trickle-bed reactor. Catalysis Today, v. 79-80, p. 427-431, 2003.

TUKAC, V.; SIMICKOVÁ, M.; CHYBA, V.; LEDERER, J.; KOLENA, J.; HANIKA, J.; JIRICNY, V.; STANEK, V.; STAVÁREK, P. The behavior of pilot trickle-bed reactor under periodic operation. Chemical Engineering Science, v. 62, p. 4891-4895, 2007. 